\title{
Tannin-Rich Extract of Chasmanthera dependens Stem Potential in Piroxicam-Induced Nephrotoxicity in Adult Male Wistar Rats
}

\author{
Tijani S. Abiola1*, Ashimolowo 0. Susan1, Babalola 0. Olusegun² \\ ${ }^{1}$ Department of Biochemistry, Bowen University, Iwo, Nigeria \\ ${ }^{2}$ Department of Biochemistry and Molecular Biology, Obafemi Awolowo University, Ife, Nigeria \\ Email: ${ }^{*}$ tijaniabiol@yahoo.com
}

How to cite this paper: Abiola, T.S., Susan, A.O. and Olusegun, B.O. (2020) Tannin-Rich Extract of Chasmanthera dependens Stem Potential in Piroxicam-Induced Nephrotoxicity in Adult Male Wistar Rats. American Journal of Molecular Biology, 10, 29-43.

https://doi.org/10.4236/ajmb.2020.101003

Received: October 4, 2019

Accepted: December 1, 2019

Published: December 4, 2019

Copyright $\odot 2020$ by author(s) and Scientific Research Publishing Inc. This work is licensed under the Creative Commons Attribution International License (CC BY 4.0).

http://creativecommons.org/licenses/by/4.0/

(c) $\underset{\mathrm{EY}}{\mathrm{C}}$ Open Access

\begin{abstract}
Piroxicam is commonly used as anti-inflammatory and pain relieving drug; however, its side effects include fluid retention, renal damage and heart failure. This study aimed at evaluating the nephroprotective role of different doses of the tannin-rich extract of Chasmanthera dependens stem (TRECDS) on piroxicam-induced nephrotoxicity in adult male Wistar rats. Thirty-two adult rats were divided into four groups of eight rats per group and treated orally for ten days. Rats in group one received $0.5 \mathrm{ml}$ normal saline $(0.9 \% \mathrm{v} / \mathrm{v})$ and served as normal control group. Rats in group two received $20 \mathrm{mg} / \mathrm{kg}$ body weight piroxicam alone. Rats in groups three and four received 20 $\mathrm{mg} / \mathrm{kg}$ body weight of piroxicam with concomitant administration of 200 and $400 \mathrm{mg} / \mathrm{kg}$ body weight of TRECDS. At the expiration of the experiment, rats were sacrificed and the kidney was removed. Renal function was evaluated. The results showed that administration of piroxicam alone caused a significant elevation in the serum concentrations of albumin, creatinine, total protein, urea concentrations and the activity of renal nucleotidase with a reduction in the activity of glucose-6-phosphate dehydrogenase (G6PD) when compared to normal control ( $\mathrm{p}<0.05)$. Furthermore, renal tissue from the piroxicam alone treated group revealed a significant decrease in the activities of renal superoxide dismutase, catalase, glutathione peroxidase and glutathione-S-transferase as well as reduced glutathione with concomitant increase in lipid peroxidation and hydrogen peroxide generation. In addition, histological assessment of the renal tissue showed noticeable damage in piroxicam alone treated group. However, concomitant administration of TRECDS showed a dose-dependent reduction in the concentrations and the activity of the kidney markers with significant increase in the activities of G6PD and restores the antioxidant status of the kidney. The results show the nephroprotective
\end{abstract}


potential of TREDS against piroxicam-induced renal damage.

\section{Keywords}

Nephrotoxicity, Chasmanthera dependens, Tannin-Rich, Anti-Inflammatory

\section{Introduction}

Piroxicam is one of the non-steroidal anti-inflammatory drugs commonly used as anti-inflammatory antipyretic and analgesic drug; however, its side effects include fluid retention, renal damage [1] [2] and heart failure. The kidney is a highly specialized organ that preserves the internal environment of the body by selectively excreting or retaining various substances according to exact body needs [3]. The capability of the kidney to concentrate the tubular fluid by removing water and salts predisposes the kidney to toxic chemicals. The biotransformation of chemicals to reactive and potentially toxic metabolites is a main feature of renal toxicity [4]. Since the kidney not only excretes the metabolic substances, but also toxic agents from the body coupled with factors like high levels of toxins delivered to the kidney, large surface area of renal tubular epithelium, specific transport mechanisms that mediate cellular uptake and normal concentrating mechanism of kidney, make kidney particularly prone to actions of nephrotoxic drugs.

The critical regulations of the body's salt, potassium and acid content as well as hormone synthesis are all functions of the kidney. In kidney damage, the kidney fails to excrete the metabolic wastes from the body leading to their accumulation and disturbance in the ionic and electrolyte balance. The kidney also makes prostaglandins and the endogenous renal prostaglandins appear to play a role in the regulation of renal hemodynamics [2], renal salt and water excretion [5], and control of the level of activity of the renin-angiotensin system [6]. The administration of non-steroidal anti-inflammatory drugs like piroxicam blocks cyclooxygenase activity [7], an early step in the synthesis of prostaglandins. This class of drugs, under certain circumstances, leads to sodium retention, hyperkalemia and several different forms of acute and chronic renal failure [2] [8].

The antioxidants status in humans reflects the vigorous balance between the antioxidant defense and prooxidant conditions and has been proposed as a useful tool in assessing the risk of oxidative damage [9] [10]. It has been shown that animals possess effective mechanism to prevent the free radical induced tissue damage via a set of endogenous antioxidant system and protein. When the balance between reactive oxygen species (ROS) production and antioxidant defense is lost oxidative stress results; which through a series of events deregulates the cellular functions leading to various pathological conditions [11].

The alternative use of ethnomedicinal plants above synthetic drugs is on the increase in recent times due to their multiple therapeutic functions and less side 
effects [12] [13]. Extracts of these plants have been reported to show protective effects against nephrotoxic agents [14]. These plants also contain some phytochemical constituents that scavenged free radical generated in the body. It has also been reported that these phytochemical constituents activate the RNA and protein syntheses which are important in the repair of renal cells.

Chasmanthera dependens is widely distributed and commonly planted in home gardens [15] (Mosango, 2008). Chasmanthera dependens is rich in alkaloids and contains the quaternary protoberberine alkaloids and the non-phenolic quaternary alkaloids, steroids, oleic acid, tannin and phenol [15]. Chasmanthera dependens is widely used in traditional medicine but very few pharmacological tests have been done. It is used topically on sprained joints and bruises [16], has also been reported to possess analgesic and anti-inflammatory effects on laboratory animals [17] [18] and as a remedy for venereal discharges or as a general tonic for physical or nervous weakness in inflammatory and exhausting diseases.

In this perspective, an effort to decipher nephroprotective activities of tannin-rich extract of Chasmanthera dependens in systematic and mechanistic ways is relevant.

\section{Materials and Methods}

\subsection{Chemicals}

Glucose-6-phosphate, adenosine monophosphate (AMP), trichloroacetic acid (TCA), Reduced glutathione (GSH), thiobarbituric acid (TBA), bovine serum albumin (BSA), Folin-Ciocalteau reagent, Ellman's Reagent [5'-5'-dithiobis-(2dinitrobenzoic acid), DNTB), epinephrine, methanol, sodium hydroxide, glacial acetic acid, thiobarbituric acid (TBA), 1-Chloro-2,4-dinitrobenzene (CDNB), tris base, hydrogen peroxide, gum acacia, sulphosalicylic acid were purchased from Sigma Aldrich Chemical Co. (St. Louis, MO, USA). Cholesterol kit, Glucose-6-phosphate dehydrogenase (G6PDH), urea kit and creatinine kit from Randox Chemicals. Others chemicals and reagents used were of analytical grade.

\subsection{Drug}

Piroxicam (manufactured by Hingbo Dahongying pharmaceutical Co. Ltd, China), was purchased from the Pharmacy unit of Bowen University Teaching Hospital (BUTH), Iwo, Osun State. The tablets were dissolved in appropriate volume of sterile distilled water according to the required concentrations needed for administration to the rats on the basis of their body weight.

\subsection{Plant Materials}

Chasmanthera dependens stems were collected in July 2017 from Iwo, Osun state, Nigeria. Iwo is located on latitude $7.6292^{\circ} \mathrm{N}$ and longitude $4.1872^{\circ} \mathrm{E}$. The plant material was identified and authenticated by Mr. Esimekhuai DPO at the Department of Botany of the University of Ibadan, Nigeria voucher specimen (UIH-22478) was deposited at the University herbarium. 


\subsection{Preparation of the Extract}

The shade dried Chasmanthera dependens stems were pulverized into coarse powders using an electric blender (Bajaj bravo 3 jars mixer grinder/blender, India), weighed and kept in air-tight container prior to extraction. $500 \mathrm{~g}$ of powdered $C$. dependens was extracted with 2.5 Litres of $70 \%$ acetone and then heated for 15 minutes. The flask was removed from the hot plate and filtered with cheese cloth. In another flask, 2 Litres of $70 \%$ acetone was then used to wash off the residue. The washed solution was combined with the filtrate. The filtrate was subjected to extraction using diethyl ether, and this was repeated five times, until a complete separation of diethyl ether and tannin extract. The tannin extract was collected using a separating funnel. The collected tannin was evaporated using rotary evaporator at $40^{\circ} \mathrm{C}$. The tannin extract was then air dried to obtain a solid mass of tannin-rich extract of Chasmanthera dependens stem (TRECDs) and stored at $-4^{\circ} \mathrm{C}$ until ready to use.

\subsection{Experimental Animals Design}

Thirty two adult male Wistar rats weighing $(150 \pm 20 \mathrm{~g})$ were purchased from the Central Animal House, Faculty of Basic Medical Science, College of Medicine, University of Ibadan, Nigeria. Animals were kept in a temperature-controlled room $\left(25^{\circ} \mathrm{C} \pm 2^{\circ} \mathrm{C}\right)$ with $12 \mathrm{~h}$ light and $12 \mathrm{~h}$ dark cycle. The rats were kept in polypropylene cages under standard laboratory conditions and were fed with standard rat's pellet (Ladokun Feeds, Nigeria) with fresh water ad libitum. They were acclimatized for 14 days. All the animals received humane care according to the criteria outlined in the "Guide for the Care and Use of Laboratory Animals" prepared by the National Academy of Science and published by the National Institute of Health [19]. The experiment was performed according to the guidelines and approval of institutional animal ethics committee.

Rats were deprived of food for 24 hours but had free access to clean water prior to the commencement of the experiment. The rats were divided into 4 groups of 8 rats in each group and treated orally once daily for ten days. Rats in group one served as normal control and received $0.5 \mathrm{ml}$ normal saline $(0.9 \%$ $\mathrm{v} / \mathrm{v})$, rats in group two received $20 \mathrm{mg} / \mathrm{kg}$ body weight piroxicam alone, rats in group three received $20 \mathrm{mg} / \mathrm{kg}$ body weight of piroxicam with concomitant administration of $200 \mathrm{mg} / \mathrm{kg}$ body weight of TRECDs and rats in group four received $20 \mathrm{mg} / \mathrm{kg}$ body weight of piroxicam with concomitant administration of $400 \mathrm{mg} / \mathrm{kg}$ body weight of TRECDs. On the eleventh day, all the rats were humane sacrificed and blood was collected separately from each rat by retro-orbital bleeding, dispensed into anti-coagulant free bottle and allow clotting at room temperature $\left(28^{\circ} \mathrm{C}\right)$ then centrifuged at $3000 \mathrm{~g}$ for ten minutes to obtain serum. The serum obtained was stored at $-20^{\circ} \mathrm{C}$ and used for evaluation of renal dysfunction markers. The kidney from each rat was also collected into separate tube, rinsed with ice-cold saline, blotted and weighed then homogenized with ice-cold $50 \mathrm{mM}$ Tris- $\mathrm{HCl}$ buffer ( $\mathrm{pH}$ 7.4) containing 1.15\% potassium chloride 
using ultra homogenizer. The homogenate was centrifuged at 10,000 $\mathrm{g}$ for fifteen minutes. The supernatant was collected into separate tubes, stored at $-20^{\circ} \mathrm{C}$ and used for the antioxidant assays.

\subsection{Serum Biochemistry}

The levels of serum urea, creatinine, albumin and Renal-5'-Nucleotidase were estimated by Fawcett and Scott [20], Henry [21] and George et al. [22] were evaluated spectrophotometrically by an Ultrospec $2000^{\circledR}$ spectrophotometer (Pharmacia Biotech, Uppsala, Sweden) in accordance with the methods provided by the diagnostic kits (Randox Laboratories Limited, UK) respectively. Serum electrolytes (sodium, potassium, chloride, and bicarbonate ions) were determined by flame photometry.

\subsection{Biochemical Assay}

Portions of kidney were weighed and homogenized in $50 \mathrm{mM}$ Tris- $\mathrm{HCl}$ buffer ( $\mathrm{pH}$ 7.4) containing $1.15 \%$ potassium chloride. Following the centrifugation of the homogenate at $10,000 \times \mathrm{g}$ for 15 minutes at $4^{\circ} \mathrm{C}$, the supernatant was collected for the estimation of superoxide dismutase (SOD) activity by the method of Misra and Fridovich [23]. Catalase (CAT) activity was assayed by using $\mathrm{H}_{2} \mathrm{O}_{2}$ as the substrate according to the method of Clairborne [24]. Protein concentration was determined by the method of Lowry et al. [25]. Glutathione (GSH) level was estimated at $412 \mathrm{~nm}$ using the method described by Jollow et al. [26]. Activity of glutathione peroxidase (GPx) was determined by the method of Rotruck et al. [27]. Glutathione-S-transferase (GST) was assayed by the method of Habig et al. [28]. Hydrogen peroxide generation was assessed by the method of Wolff [29]. Lipid peroxidation was quantified as malondialdehyde (MDA) according to the method described by Farombi et al. [30] and expressed as micromoles of MDA per milligram protein.

\subsection{Histopathology}

Kidney biopsy was processed for histology according to Songur et al. [31]. Briefly, kidney specimens were fixed in $10 \%$ neutral buffered formaldehyde solution. After dehydration procedures, the samples were blocked in paraffin. Sections of $4-5 \mu \mathrm{m}$ were cut by a microtome and stained with hematoxylin and eosin ( $\mathrm{H} \&$ E). All slides were coded before examination with light microscope and photographed using a digital camera by investigators who were blinded to control and drug-treated groups.

\subsection{Statistical Analyses}

All the results were expressed as mean \pm SEM. Statistical analyses were carried out using one-way analysis of variance (ANOVA) and Duncan's multiple comparisons test using Statistical packages for social Scientists version 18.0 (SPSS version 18.0). Value of $p<0.05$ was considered statistical significant. 


\section{Results}

\section{Protective effect of TRECDs on piroxicam-induced kidney dysfunction}

To investigate the integrity of the kidney following piroxicam administration to rats, the concentrations of biomarkers of renal dysfunction were determined. The effects of piroxicam on $\mathrm{Na}^{+}, \mathrm{K}^{+}, \mathrm{Ca}^{2+}, \mathrm{PO}_{4}^{2-}, \mathrm{HCO}_{3}^{-}, \mathrm{Cl}^{-}$, urea, creatinine, albumin levels and renal-5'-nucleotidase activity in the rats are shown in Table 1 and Figure 1 respectively. The result indicated that piroxicam administration to

Table 1. Biomarkers of renal dysfunction in rats exposed to piroxicam and TRECDs.

\begin{tabular}{ccccc}
\hline Parameters & Control & Pirox Alone & Pirox + TRECDs1 & Pirox + TRECDs2 \\
\hline $\mathrm{Na}^{+}(\mathrm{mmol} / \mathrm{L})$ & $118.12 \pm 0.14$ & $145.68 \pm 0.98$ & $128.03 \pm 0.19^{* \$}$ & $112.08 \pm 1.20^{* *}$ \\
$\mathrm{~K}^{+}(\mathrm{mmol} / \mathrm{L})$ & $4.21 \pm 0.04$ & $9.04 \pm 0.79$ & $2.18 \pm 0.21^{* \$}$ & $3.98 \pm 0.12^{\star *}$ \\
$\mathrm{Ca}^{2+}(\mathrm{mmol} / \mathrm{L})$ & $2.10 \pm 0.02$ & $4.67 \pm 0.05$ & $3.12 \pm 0.25^{* \$}$ & $2.22 \pm 0.45^{\star *}$ \\
$\mathrm{HCO}_{3}^{-}(\mathrm{mmol} / \mathrm{L})$ & $12.05 \pm 0.16$ & $23.25 \pm 0.26$ & $9.06 \pm 0.17^{* \$}$ & $13.45 \pm 0.78^{\star *}$ \\
$\mathrm{Cl}^{-}(\mathrm{mmol} / \mathrm{L})$ & $54.32 \pm 0.24$ & $78.64 \pm 1.06$ & $65.12 \pm 1.23^{\star \$}$ & $56.19 \pm 0.98^{* *}$ \\
$\mathrm{PO}_{4}^{2-}(\mathrm{mmol} / \mathrm{L})$ & $3.32 \pm 0.25$ & $6.45 \pm 0.21$ & $4.23 \pm 0.22^{* \$}$ & $3.65 \pm 0.12^{* *}$ \\
\hline
\end{tabular}

Each represents mean \pm standard error of mean. ${ }^{*} p<0.05$ is significant when compared with the piroxicam alone group, ${ }^{*} \mathrm{p}<0.05$ is significant when compared with the Pirox + TRECDs 1 group. ${ }^{s} \mathrm{p}<0.05$ is significant when compared with the Pirox + TRECDs2 group.

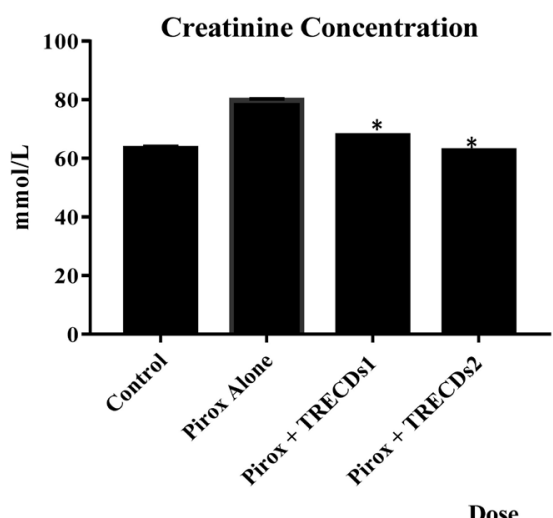

Albumin Concentration

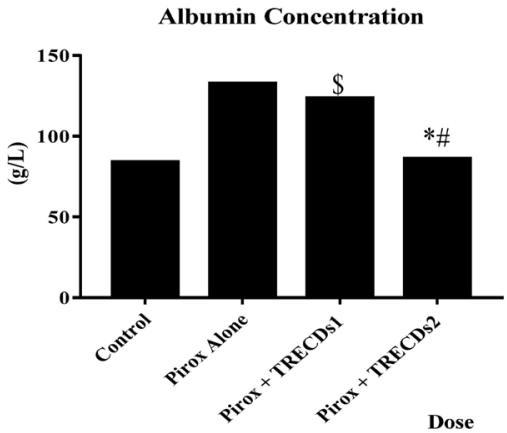

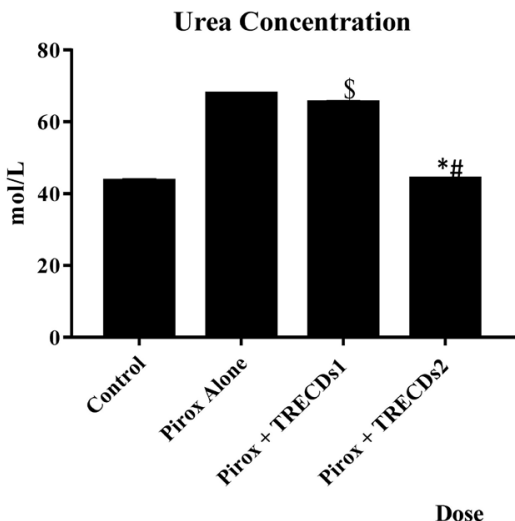

Renal-5'-Nucleotidase Activity

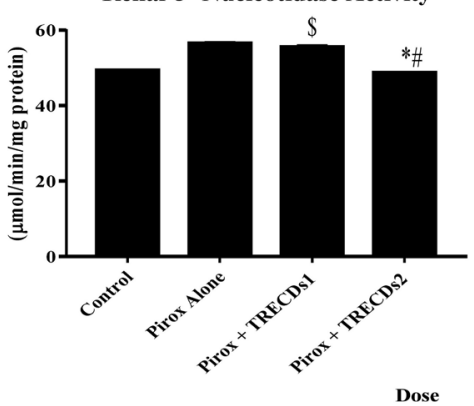

Each represents mean \pm standard error of mean. ${ }^{*} \mathrm{p}<0.05$ is significant when compared with the piroxicam alone group, ${ }^{\#} \mathrm{p}<0.05$ is significant when compared with the Pirox + TRECDs1 group. ${ }^{\$} \mathrm{p}<$ 0.05 is significant when compared with the Pirox + TRECDs2 group.

Figure 1. Effect of tannin-rich extract of Chasmanthera dependens stem on biomarkers of renal dysfunction in rats exposed to piroxicam. 
rats caused a significant elevation in the concentration of serum albumin, creatinine, urea and renal-5'-nucleotidase activity and all the electrolytes levels when compared with the control. However, concomitant administration of 200 and $400 \mathrm{mg} / \mathrm{kg}$ body weight of TRECDs restored the integrity of the kidney by decreasing the levels and the activity of all the tested parameters.

\section{Effect of TRECDs on piroxicam-induced oxidative stress}

Following administration of piroxicam, the antioxidant statuses of the kidney of the treated rats was determined using a panel of assays including enzymatic and non-enzymatic antioxidant levels along with hydrogen peroxide and lipid peroxidation levels. Figure 2 and Figure 3 show the effects of piroxicam on the renal antioxidant status in the experimental rats. Repeated exposure to piroxicam for 10 days caused a significant $(\mathrm{p}<0.05)$ decrease in the activities of antioxidant enzymes SOD, CAT, GPx and GST in kidney of the piroxicam alone treated group when compared with the control animals. However, the significant decrease in the level of GSH was accompanied by a significant increase in the levels of $\mathrm{H}_{2} \mathrm{O}_{2}$ generation and MDA levels, a biomarker of lipid peroxidation in a dose-dependent manner in the renal tissues of rats following 10 consecutive days of treatment with piroxicam when compared with the control values. But, concomitant administration of TRECDs with piroxicam reversed all these observations. Furthermore, administration of piroxicam for 10 days also decreased the activities of G6PD.
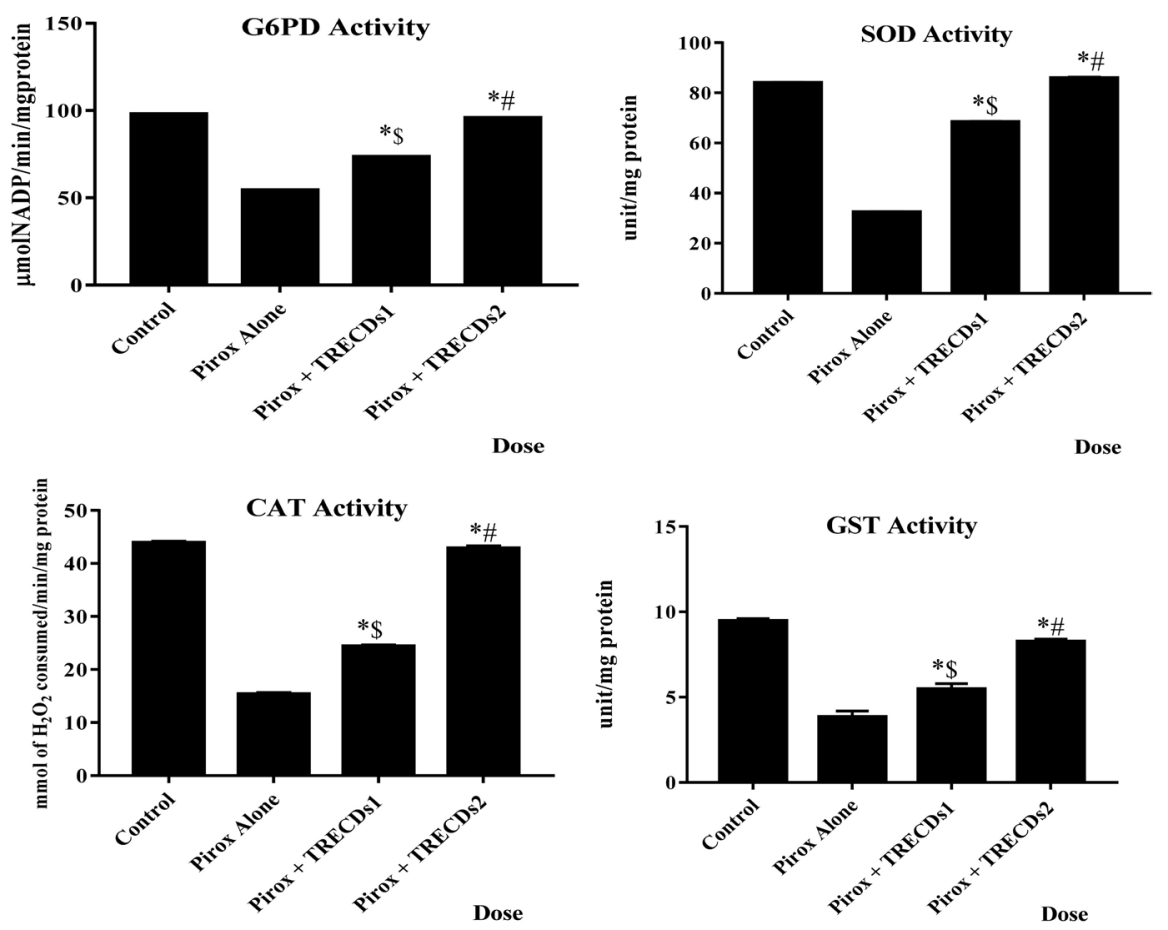

Each represents mean \pm standard error of mean. ${ }^{*} \mathrm{p}<0.05$ is significant when compared with the piroxicam alone group, ${ }^{*} \mathrm{p}<0.05$ is significant when compared with the Pirox + TRECDs group $1 .{ }^{\$} \mathrm{p}<$ 0.05 is significant when compared with the Pirox + TRECDs2 group. G6PD: glucose-6-phosphate dehydrogenase; SOD: superoxide dismutase; CAT: catalase and GST: glutathione-S-transferase.

Figure 2. Effect of TRECDs on piroxicam-induced oxidative stress markers in kidney of rats. 

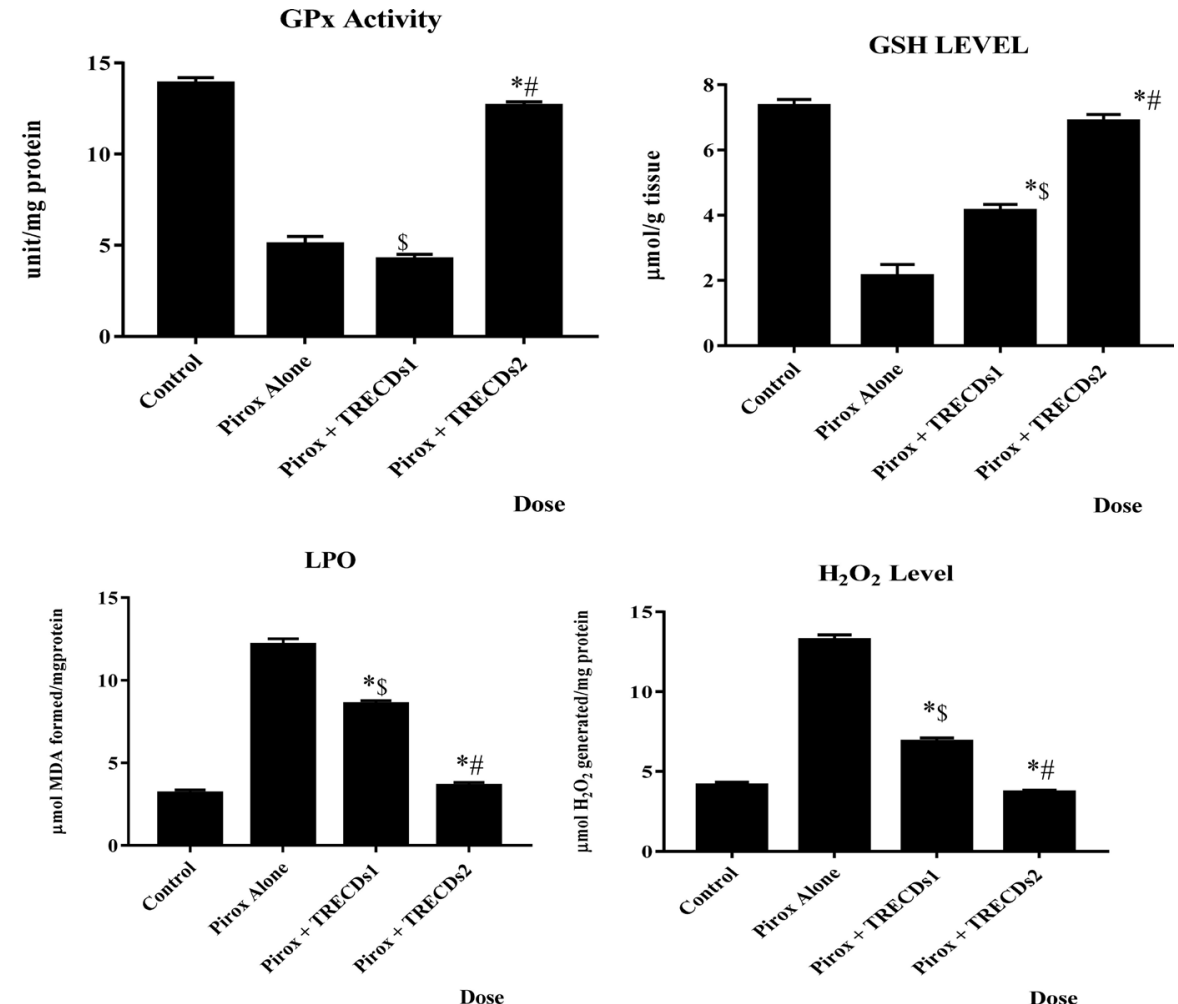

Each represents mean \pm standard error of mean. ${ }^{*} \mathrm{p}<0.05$ is significant when compared with the piroxicam alone group, ${ }^{*} \mathrm{p}<0.05$ is significant when compared with the Pirox + TRECDs group $1 .{ }^{\$} \mathrm{p}<$ 0.05 is significant when compared with the Pirox + TRECDs2 group. GPx: glutathione peroxidase; GSH: glutathione; LPO: lipid peroxidation and $\mathrm{H}_{2} \mathrm{O}_{2}$ : hydrogen peroxide.

Figure 3. Effect of TRECDs on activity of GPx and levels of GSH, LPO and $\mathrm{H}_{2} \mathrm{O}_{2}$ on piroxicam-induced kidney damage in rats.

\section{Discussion}

Kidney damage is associated with deterioration in renal function which could lead to renal failure. The decrease in renal function evidenced by significant increase in plasma levels of urea and creatinine in rats treated with piroxicam alone was clearly demonstrated in the present investigation. While an increase in serum urea may indicate decrease in reabsorption at the renal epithelium, an increase in serum creatinine reflects impairment in the kidneys, especially for glomerular filtration rate [4]. The increase observed in the serum level of creatinine and urea is in accordance with the report of [32]. The data on the renal function parameters observed in the present study following oral administration of piroxicam to rats, corroborated the adverse effect of piroxicam on renal function. However, administration of different doses of TRECDs produced a dose-dependent decrease in the levels of these markers; this is in agreement with the work of [33].

Albumin, a predominant protein filtered by the glomerulus in the kidney. The presence of increased concentrations of albumin in the kidney indicates a dysfunctional glomerulus. The result of this study showed that the piroxicam alone treated group had the highest concentration of albumin, this is in accordance 
with the report of [34] showing that piroxicam led to a reduction in GFR resulting in albumin retention in the nephrons. However, rats treated with 200 and $400 \mathrm{mg} / \mathrm{kg}$ body weight of TRECDs, there was a dose-dependent decrease in the concentration of albumin this is also in agreement with the report of [35].

Glucose-6-phosphate dehydrogenase (G6PD) is the rate-limiting enzyme of the pentose phosphate pathway and the main source of the essential cellular reductant, NADPH. NADPH is required for many essential cellular processes such as the antioxidant system, nitric oxide synthase, cytochrome p450 enzymes and NADPH oxidase [36]. The decrease in the activity of G6PD in piroxicam alone treated group is in accordance with the report of [37]. However, concomitant administration of TRECDs revealed a dose-dependent increase in the activity of G6PD.

Renal nucleotidase; a suitable marker enzyme for plasma membranes cleaves phosphate group from purine nucleotides AMP and GMP to produce adenosine and guanine. It regulates renal hemodynamics, GFR and renin release via specific receptors of the arteriolar walls [38]. In this study, renal nucleotidase activity rapidly increased in the piroxicam alone treated group compared, this is in accordance with the report of [38]. Furthermore, rats treated with different doses of TRECDs alongside piroxicam showed decreased activity of this enzyme, this is in agreement with the report of [39].

Electrolytes are important ions in the maintenance of homeostasis, normal functioning of neurotransmitters, acid-base balance, regulation of blood pressure maintenance of healthy bones and teeth. Increase in these electrolytes in renal tissues indicates renal dysfunction. Sodium is one of the most important electrolytes in the body and a major extracellular cation. It is of important in maintenance of blood pressure via the angiotensin-renin system. Potassium is a major intracellular cation which is vital to the healthy functioning of all body's cells, tissues and organs. It is also essential for muscular function. A balance of sodium and potassium is important for the body's electrolyte functions. As an electrolyte, bicarbonate is important for maintenance of acid-base homeostasis. Disturbance of acid-base homeostasis is one of the biochemical features of kidney damage.

The significant elevation in the serum $\mathrm{Na}^{-}, \mathrm{K}^{+}, \mathrm{HCO}_{3}^{-}$, and $\mathrm{Cl}^{-}$levels in this present study is of toxicological significance and may indicate a consequential effect on the ion-dependent processes in the piroxicam-treated animals. Based on the serum biochemical parameters presented in the present study, piroxicam exposure induced renal damages in the treated rats. Administration of TRECDs decreased the levels of these electrolytes in a dose-dependent manner and values obtained were very close to the values obtained for the control group. From the results it is clear that as the dose of TRECDs increases the level of protection of the kidney integrity was increased.

It is well-known that as kidney function declines, there is a progressive deterioration in mineral homeostasis, with a disruption of normal serum and tissue 
concentrations of phosphorus, calcium, and changes in circulating levels of hormones [40]. Phosphorus is an essential mineral required for cell structure, signaling, energy transfer, and other important functions. It serves as a reservoir for temporary storage and transfer of energy and as an acid-base buffer, and forms the structural components of cells (e.g. phospholipids, nucleotides, and nucleic acids). Derangement in the concentration of phosphorus as a result of drug intake could have adverse consequences on the skeletal, renal, and cardiovascular systems. The disturbances of bone mineral metabolism have been linked to increased risk of renal disease, end-stage renal disease (ESRD), cardiovascular disease (CVD) and death.

From this study, there was a significant increase in the level of phosphate in group of rats treated with piroxicam alone when compared with control group at $\mathrm{p}<0.05$. This is in line with precipitation-calcification hypothesis; calcium phosphate crystal deposition in the renal parenchyma may leads to inflammation, neprocalcinosis and kidney injury [41].

Animal studies demonstrate a direct relationship between phosphorus load per nephron and renal parenchymal calcification and proximal tubular injury. There is increasing evidence of extra skeletal calcification that may result from the deranged mineral and bone metabolism in renal disease as seen in calcium and phosphate concentration in serum and tissues [42]. The concentration of calcium in kidney homogenate was significantly increased in piroxicam-alone treated group (mean of $0.73 \pm 0.29 \mathrm{mg} / \mathrm{dl}$ ) compared with control group $(0.25 \pm$ $0.12 \mathrm{mg} / \mathrm{dl}$ ) at $\mathrm{p}<0.05$. However, this was reversed by administration of TRECD showing that TRECDS is a remedy for mineral and bone disorders associated with/as a result of Piroxicam induced nephrotoxicity.

In an attempt to explain the mechanism of action of piroxicam at subcellular levels in the kidney, we investigated its influence on the renal antioxidant status. Normally the deleterious effects of oxidative stress are counteracted by the natural antioxidant defense mechanisms to protect the biological system against reactive oxygen species. Antioxidant statuses are regulated by multiple factors. The oxidative status of the cell is the primary factor regulating gene expression and the activity of antioxidant enzymes [43]. Superoxide dismutase (SOD), catalase (CAT), glutathione peroxidase (GPx), and glutathione-S-transferase (GST) are endogenous antioxidant enzymes responsible for the detoxification of deleterious oxygen radicals and their activities are used to assess oxidative stress in cells [3] [44]. The first line of defense to the cells is provided by the existence of a mutually supportive relationship between metalloenzymes SOD, which accelerates the dismutation of endogenous cytotoxic superoxide radicals to $\mathrm{H}_{2} \mathrm{O}_{2}$, and CAT, which converts the deleterious peroxide radicals into water and oxygen [45].

In the present study, the activities of renal SOD, CAT, GPx, and GST were markedly decreased in rats that received piroxicam alone. The decrease in the activities of these antioxidant enzymes indicate the damaging effect of oxidative stress possibly generated during piroxicam metabolism. Glutathione plays a pi- 
votal role in the scavenging of hydroxyl radical and singlet oxygen directly as well as in the detoxification of hydrogen peroxides and lipid hydroperoxides via the activity of GPx. Further, GST is involved in the biochemical conjugation of electrophilic oxidants with GSH to form water soluble compound products that are readily excreted from the system [28] [46]. The observed decrease in the renal GSH level in the present study may suggest an increased demand or overutilization of GSH by the cell possibly to combat ROS generation in the piroxicam-treated rats. The deleterious chemical effects of $\mathrm{H}_{2} \mathrm{O}_{2}$ molecules can be grouped into the categories of direct activity, originating from their oxidizing properties, and indirect activity in which they serve as a source for more deleterious species, such as hydroxyl radicals and hypochlorous acid [47]. Reactive oxygen species attack cellular components containing polyunsaturated fatty acid residues to produce peroxyl radicals which undergo a cyclization reaction to form endoperoxides and eventually trans-4-hydroxy-2-nonenal and MDA [48]. The dose-dependent increases in the renal $\mathrm{H}_{2} \mathrm{O}_{2}$ and MDA levels observed in this study clearly demonstrate a state of stress in the tissues possibly induced by piroxicam or its metabolites.

The histopathological report revealed that oral administration of piroxicam alone produced remarkable damaging effect to kidney of the treated rats, hence supporting the observed biochemical observations. The piroxicam alone treated group showed lesions as advanced degeneration of the proximal tubules depicted by mild hemorrhage at interstitium in tubular epithelial cells with severe vacuolation and renal tubular necrosis (red arrows). However, as the doses of the TRECDs increases the architectural integrity of the kidneys was practically restored (Figure 4).
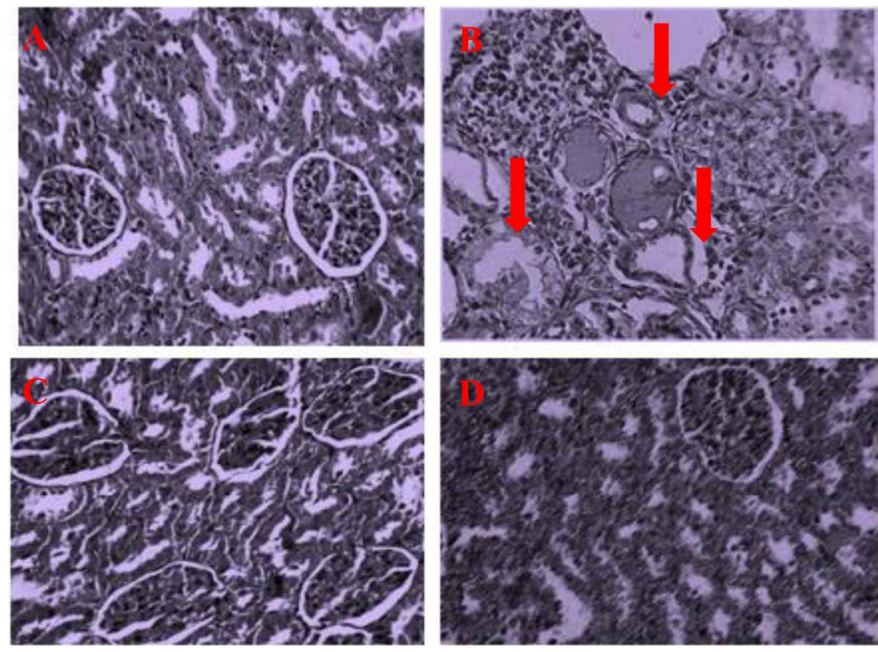

Figure 4. Influence of piroxicam on kidney morphology of control, piroxicam- and TRECDs-administered rats. Representative photomicrographs of control (A) show normal renal architecture; (B) kidney histology revealed progressive degeneration of the proximal tubules characterized by mild edema (arrow) at interstitium in tubular epithelial cells in piroxicam alone treated group; (C) Pirox $+200 \mathrm{mg} / \mathrm{kg}$ TRECDs showed mild degeneration of the proximal tubules; (D) Pirox $+400 \mathrm{mg} / \mathrm{kg}$ TREDs revealed restoration of the kidney architecture. 


\section{Conclusion}

The present study clearly demonstrates that exposure to piroxicam is capable of inflicting biological damage leading to the pathology of many conditions including kidney damage. The differential detrimental effects of piroxicam on kidney in rats are closely associated with biochemical changes including impairment of function, metabolic disorders, oxidative stress, and histological alteration. The data presented herein are novel and show, for the first time, that the renal toxicity of piroxicam in the experimental rats is presumably by increased generation of ROS which led to perturbation of antioxidant defense systems and that tannin-rich extract of Chasmanthera dependens has the ability to reverse the adverse effects of piroxicam. Hence, the extrapolation of the present animal study to human indicates that piroxicam has potential health risk in exposed individuals and that tannin-rich extract of Chasmanthera dependens has the capacity to protect the kidney integrity against drug-induced damage.

\section{Conflicts of Interest}

The authors declare no conflicts of interest regarding the publication of this paper.

\section{References}

[1] Gambaro, G. and Perazella, M.A. (2003) Adverse Renal Effects of Anti-Inflammatory Agents: Evaluation of Selective and Nonselective Cyclooxygenase Inhibitors. Journal of International Medicine, 253, 643-652. https://doi.org/10.1046/j.1365-2796.2003.01146.x

[2] Neha, R., Munna, S. and Sanghamitra, R. (2015) Piroxicam, a Traditional Non-Steroidal Anti-Inflammatory Drug (NSAID) Causes Apoptosis by ROS Mediated Akt Activation. Pharmacological Reports, 67, 1215-1223. https://doi.org/10.1016/j.pharep.2015.05.012

[3] Liu, C.M., Ma, J.Q. and Sun, Y.Z. (2010) Quercetin Protects the Rat Kidney against Oxidative Stress-Mediated DNA Damage and Apoptosis Induced by Lead. Environmental Toxicology and Pharmacology, 30, 264-271. https://doi.org/10.1016/j.etap.2010.07.002

[4] Adedara, I.A., Teberen, R., Ebokaiwe, A.P., Ehwerhemuepha, T. and Farombi, E.O. (2012) Induction of Oxidative Stress in Liver and Kidney of Rats Exposed to Nigerian Bonny Light Crude Oil. Environmental Toxicology, 27, 372-379. https://doi.org/10.1002/tox.20660

[5] Weir, M.R. (2002) Renal Effects of Nonselective NSAIDs and Coxibs. Cleveland Clinic Journal of Medicine, 69, SI53-SI58. https://doi.org/10.3949/ccjm.69.Suppl_1.SI53

[6] Harris, R.C. (2006) COX-2 and the Kidney. Journal of Cardiovascular Pharmacology, 47, S37-S42. https://doi.org/10.1097/00005344-200605001-00007

[7] Buer, J. (2104) Origins and Impact on the Term 'NSAID'. Inflammopharmacology, 22, 263-267. https://doi.org/10.1007/s10787-014-0211-2

[8] Omudhome, O. (2017) Piroxicam. http://www.medicinenet.com

[9] Nose, K. (2000) Role of Reactive Oxygen Species in the Regulation of Physiological 
Functions. Biological and Pharmaceutical Bulletin, 23, 897-903. https://doi.org/10.1248/bpb.23.897

[10] Polidori, M.C., Stahl, W., Eichler, O., Niestroj, I. and Sies, H. (2001) Profiles of Antioxidants in Human Plasma. Free Radical Biology and Medicine, 30, 456462. https://doi.org/10.1016/B978-0-444-50957-4.50037-5

[11] Dey, A. and Loukshmanan, J. (2013) The Role of Antioxidant and Other Agents in Alleviating Hyperglycemia-Mediated Oxidative Stress and Injury in Liver. Food Function, 4, 1148-1184. https://doi.org/10.1039/c3fo30317a

[12] Channabasava, G.M., Chandrappa, C.P. and Umashankar, T. (2015) Gc-Ms Study of Two Column Fractions from Methanol Extracts of Loranthus micranthus and Their in-Vivo Antidiabetic Activity on Alloxan Induced Diabetic Rats. Journal of Diabetes Metabolism, 6, 5-14.

[13] Adejuwon, S.A., Omirinde, J.O., Ebokaiwe, A.P., Aina, O.O., Adenipekun, A. and Farombi, E.O. (2014) Radiation-Induced Testicular Injury and Its Amelioration by Telfairia occidentalis. British Journal of Medicine Medical Research, 4, 7-18. https://doi.org/10.9734/BJMMR/2014/8235

[14] Rasikh, J., Mohd, A., Qudsia, N. and Rasheela, J. (2012) Role of Antioxidant Herbal Drugs in Renal Disorders: An Overview. Free Radicals and Antioxidants, 2, 2-5. https://doi.org/10.5530/ax.2012.2.2

[15] Mosango, D. (2008) Chasmanthera dependens Hochst. Record from Protabase. In: Schmelzer, G.H. and Gurib-Fakim, A., Eds., PROTA (Plant Resources of Tropical Africal Ressourcesvégétales de I Afriquetropicale), Wageningen, Netherlands, 23-45.

[16] Ogunlesi, M., Okei, W. and Ademoye, M. (2008) Medicinal Plants Used in Treating Eye Infections in Nigeria. In: Odugbemi, T., Ed., A Textbook of Medicinal Plants from Nigeria, University of Lagos Press, Lagos, 299-317.

[17] Morebise, O., Awe, E.O., Makinde, J.M. and. Olajide, O.A. (2001) Evaluation of the Anti-Inflammatory and Analgesic Properties of Chasmanthera dependens Leaf Methanol Extract. Fitoterapia, 72, 497-502. https://doi.org/10.1016/S0367-326X(01)00274-X

[18] Fatokun, O.T., Wojuola, T.E., Esievo, K.B. and Kunle, O.F. (2016) Medicinal Plants Used in the Management of Asthma: A Review. European Journal of Pharmaceutical and Medical Research, 3, 82-92

[19] Public Health Service (1996) Policy on Humane Care and Use of Laboratory Animals. US Department of Health and Human Services, Washington DC.

[20] Fawcett, J.K. and Scott, J.E. (1960) A Rapid and Precise Method for the Determination of Urea. Journal of Clinical Pathology, 13, 156-159. https://doi.org/10.1136/jcp.13.2.156

[21] Henry, R.J. (1974) Clinical Chemistry, Principles and Techniques. 2nd Edition, Harper and Row, Hagerstown, MD.

[22] Goodland, G.A.J. and Clark, C.M. (1982) Alteration in Hepatic 5,-Nucleotidase in Tumor Bearing Rat. Enzyme, 27, 119-123. https://doi.org/10.1159/000459035

[23] Misra, H.P. and Fridovich, I. (1972) The Role of Superoxide Anion in the Autoxidation of Epinephrine and a Simple Assay for Superoxide Dismutase. The Journal of Biological Chemistry, 247, 3170-3175.

[24] Clairborne, A. (1995) Catalase activity. In: Greewald, A.R., Ed., Handbook of Methods for Oxygen Radical Research, CRC Press, Boca Raton, FL, 237-242.

[25] Lowry, O.H., Rosenbrough, N.J., Farr, A.L. and Randall, R.J. (1951) Protein Measurement with the Folin Phenol Reagent. The Journal of Biological Chemistry, 193, 
265-275.

[26] Jollow, D.J., Mitchell, J.R., Zampaglione, N. and Gillette, J.R. (1974) Bromobenzene Induced Liver Necrosis. Protective Role of Glutathione and Evidence for 3,4 Bromobenzene Oxide as the Hepatotoxic Metabolite. Pharmacology, 11, 151-169. https://doi.org/10.1159/000136485

[27] Rotruck, J.T., Pope, A.L., Ganther, H.E., Swanson, A.B., Hafeman, D.G. and Hoekstra, W.G. (1973) Selenium: Biochemical Role as a Component of Glutathione Peroxidase. Science, 179, 588-590. https://doi.org/10.1126/science.179.4073.588

[28] Habig, W.H., Pabst, M.J. and Jakoby, W.B. (1974) Glutathione-S-Transferases. The First Enzymatic Step in Mercapturic Acid Formation. Journal of Biological Chemistry, 249, 7130-7139.

[29] Wolff, S.P. (1994) Ferrous Ion Oxidation in Presence of Ferric Ion Indicator Xylenol Orange for Measurement of Hydroperoxides. Methods in Enzymology, 233, 182-189. https://doi.org/10.1016/S0076-6879(94)33021-2

[30] Farombi, E.O., Tahnteng, J.G., Agboola, A.O., Nwankwo, J.O. and Emerole, G.O. (2000) Chemoprevention of 2-Acetylaminofluorene-Induced Hepatotoxicity and Lipid Peroxidation in Rats by Kolaviron; A Garcinia Kola Seed Extract. Food and Chemical Toxicology, 38, 535-541. https://doi.org/10.1016/S0278-6915(00)00039-9

[31] Songur, A., Akpolat, N., Kus, I., Ozen, O.A., Zararsiz, I. and Sarsilmaz, M. (2003) The Effects of the Inhaled Formaldehyde during the Early Postnatal Period in the Hippocampus of Rats: Amorphological and Immunohistochemical Study. Neuroscience Research Communications, 33, 168-178. https://doi.org/10.1002/nrc.10093

[32] Tanti-Azizah, S., Rima, M., Peppy, W. and Yuyun-Puji, L. (2014) The Protective Effect of Sarung semut Tubers Infusion on Gentamicin-Piroxicam Induced Nephrotoxicity in Rats. Indonesian Journal of Pharmacy, 25, 91-97. https://doi.org/10.14499/indonesianjpharm25iss2pp91

[33] Mongi, S., Mahfoud, M., Amel, B., Kamel, J. and Abdelfattah, F. (2011) Protective Effects of Vitamin C against Haematological and Biochemical Toxicity Induced by Deltamethrin in Male Wistar Rats. Ecotoxicological and Environmental Safety, 74, 1765-1769. https://doi.org/10.1016/j.ecoenv.2011.04.003

[34] Christian, J., Wolfgang, W. and Michael, J. (2010) Hypoalbuminemia and Acute Kidney Injury: A Meta-Analysis of Observational Clinical Studies. Intensive Care Medicine, 36, 1657-1665. https://doi.org/10.1007/s00134-010-1928-Z

[35] Kore, K. (2011) RP-HPLC Simultameous Nephroprotective Role of Aegle marelos Extract. International Journal of Research in Pharmacy and Chemistry, 1, 51-56.

[36] Spencer, N. and Stanton, R. (2017) Glucose-6-Phosphate Dehydrogenase and the Kidney. Current Opinion Nephrology and Hypertension, 26, 43-49.

https://doi.org/10.1097/MNH.0000000000000294

[37] Ozyurt, B., Gulec, M., Ozyurt, H., Ekici, F., Atis, O. and Akbas, A. (2006) The Effect of Antioxidant Caffeic Acid Phenethyl Ester (CAPE) on Some Enzyme Activities in Cisplatin-Induced Nephrotoxicity in Rats. European Journal of General Medicine, 3, 167-172. https://doi.org/10.29333/ejgm/82401

[38] Isabel, C., Klaus, H. and Hayo, C. (2012) Role of Ecto-5'-Nucleotidase (CD73) in the Development of Renal Fibrosis. The FASEB Journal, 26, 2-3.

[39] Khan, H. (2009) Studies on the Protective Effect of Green Tea against Cisplatin-Induced Nephrotoxicity. Pharmaceutical Research, 60, 382-391.

https://doi.org/10.1016/j.phrs.2009.07.007

[40] KDIGO, Clinical Practice Guideline for the Diagnosis, Evaluation, Prevention, and Treatment of Chronic Kidney Disease-Mineral and Bone Disorder (CKD-MBD) 
(2009) Introduction and Definition of CKD-MBD and the Development of the Guideline Statements. Kidney International Supplement, 76, S3-S8.

[41] Lau, K. (1989) Phosphate Excess and Progressive Renal Failure: The Precipitation-Calcification Hypothesis. Kidney International, 36, 918-937.

https://doi.org/10.1038/ki.1989.281

[42] Bover, J., Evenepoel, P., Ureña-Torres, P., Vervloet. M.G., Brandenburg, V., Mazzaferro, S., Covic, A., Goldsmith, D., Massy, Z.A. and Cozzolino, M. (2015) Pro: Cardiovascular Calcifications Are Clinically Relevant. Nephrology and Dialysis Transplant, 30, 345-551. https://doi.org/10.1093/ndt/gfv020

[43] Rodriguez, C., Mayo, J.C., Sainz, R.M., et al. (2004) Regulation of Antioxidant Enzymes: A Significant Role for Melatonin. Journal of Pineal Research, 36, 1-9. https://doi.org/10.1046/j.1600-079X.2003.00092.x

[44] Jacob, R.A. (1995) The Integrated Antioxidant System. Nutrition Research, 15, 755-766. https://doi.org/10.1016/0271-5317(95)00041-G

[45] Adedara I.A. and Farombi, E.O. (2010) Induction of Oxidative Damage in the Testes and Spermatozoa and Hematotoxicity in Rats Exposed to Multiple Doses of Ethylene Glycol Monoethyl Ether. Human and Experimental Toxicology, 29, 801-812. https://doi.org/10.1177/0960327109360115

[46] Masella, R., Di Benedetto, R., Vari, R., Filesi, C. and Giovannini, C. (2005) Novel Mechanisms of Natural Antioxidant Compounds in Biological Systems: Involvement of Glutathione and Glutathione Related Enzymes. Journal of Nutritional Biochemistry, 16, 577-586. https://doi.org/10.1016/j.jnutbio.2005.05.013

[47] Kohen, R. and Nyska, A. (2002) Oxidation of Biological Systems: Oxidative Stress Phenomena, Antioxidants, Redox Reactions, and Methods for Their Quantification. Toxicologic Pathology, 30, 620-650. https://doi.org/10.1080/01926230290166724

[48] Marnett, L.J. (1999) Lipid Peroxidation-DNA Damage by Malondialdehyde. $\mathrm{Mu}$ tation Research/Fundamental and Molecular Mechanisms of Mutagenesis, 424, 83-95. https://doi.org/10.1016/S0027-5107(99)00010-X 